\title{
Tecnologias no Ensino de Línguas: \\ Formando Professores para o Agora
}

\author{
Tecnologías en La Enseñanza de Lenguas: Formando \\ Profesores PARA EL AHORA
}

\section{Marcus Vinícius Liessem FONTANA * Vanessa Ribas FIALHO **}

Resumo: Este artigo trata de um trabalho de inclusão de uma disciplina de tecnologias em um curso de formação de professores de língua espanhola. Aqui, buscamos explicar como foi preparada e desenvolvida a disciplina: desde o projeto inicial dos professores até os resultados obtidos. Além disso, procura-se analisar tudo o que foi feito sob o ponto de vista da Teoria dos Sistemas Complexos, com base em Morin (2007) e outros autores significativos relacionados a essa teoria. Por fim, tenta-se demonstrar a importância dos estudos tecnológicos na formação dos professores modernos e a relação da teoria que é apresentada com uma nova maneira de ver a educação, mais holística e integradora.

Palavras-chave: Formação de professores; Tecnologias de informação e comunicação; Teoria dos Sistemas Complexos.

Resumen: Este artículo trata de un trabajo de inclusión de una asignatura de tecnologías en un curso de formación de profesores de lengua española. Aquí, buscamos explicar cómo se preparó y se desarrolló la asignatura: desde el proyecto inicial de los profesores hasta los resultados que se obtuvieron. Además de eso, se busca analizar todo lo que se hizo bajo el punto de vista de la Teoría de los Sistemas Complejos,

\footnotetext{
* Mestre em Linguística Aplicada. Professor Assistente da Universidade Federal de Santa Maria. Contato: marcusfontana2011@gmail.com

** Mestre em Linguística Aplicada. Professora Assistente da Universidade Federal de Santa Maria. Contato: vanessafialho@gmail.com
} 
con base en Morin (2007) y otros autores significativos relacionados a esa teoría. Al fin, se intenta demostrar la importancia de los estudios tecnológicos en la formación de los profesores modernos y la relación de la teoría que se presenta con una nueva manera de ver la educación, más holística e integradora.

Palabras-clave: Formación de profesores; Tecnologías de información y comunicación; Teoría de los Sistemas Complejos.

\section{Introdução}

"Eu sei que a Educação a Distância é o futuro", "um dia, terei que aprender a lidar com esse tal de Moodle", "eu acredito que, em breve, as tecnologias vão dominar a sala de aula". Desde que começamos a trabalhar com e a pesquisar sobre EaD, há alguns anos, temos ouvido muito esse tipo de frase de colegas de profissão. $O$ interessante - e assustador -, entretanto, é que esse discurso muito pouco tem mudado com o passar dos anos. De forma alguma temos interesse em julgar a competência profissional desses professores, porém, o fato é que essas pessoas não fazem mais do que projetar para um distante porvir uma realidade concreta que se descortina diante de nossos olhos neste exato momento. A Educação a Distância não é o futuro: é o agora!

A Universidade Aberta do Brasil (UAB), por exemplo, atualmente coordenada pela CAPES, é uma iniciativa do MEC em parceria com universidades públicas. Desde 2005, a UAB tem disseminado a ideia de um ensino mediado por ferramentas tecnológicas. Essa prática permite que professores trabalhem tranquilamente em um laboratório informatizado desde sua instituição de ensino, ou mesmo desde sua casa, e atendam a alunos que estão em outras cidades ou mesmo em outros Estados, estudando em um Polo de Assistência Presencial (PAP). Montado pelos respectivos poderes municipais, o polo é um ambiente que conta com salas de aula, laboratórios de informática, bibliotecas, além de profissionais qualificados para atender aos alunos e orientá-los em suas necessidades mais imediatas. Esses profissionais, chamados Tutores Presenciais, servem de conexão entre os alunos e as instituições de ensino. 
Longe de ser uma panaceia - sejamos realistas -, a verdade é que ninguém pode negar que muitas pessoas que hoje estão cursando o ensino superior só o fazem porque, em sua cidade lá no interior de um recanto desconhecido, surgiu um polo de EaD. Uma cidade de cinco mil habitantes ter uma universidade pública instalada localmente com todos os recursos que se esperam dela? Isso é praticamente uma utopia, mas, com o advento da Educação a Distância, tornou-se um fato.

Não pretendemos neste artigo fazer uma defesa apaixonada da EaD. Acreditamos que ela é uma realidade estabelecida e, portanto, não necessita de nós como seus salvadores ou sequer seus relações públicas. Além disso, como trabalhamos com essa modalidade de ensino, somos muito conscientes de seus problemas e de suas falhas, tanto quanto somos conscientes dos problemas e das falhas da educação presencial. Queremos, entretanto, demonstrar que negar a Educação a Distância e negar o uso de tecnologias em sala de aula corresponde a negar a própria realidade do mundo em que vivemos hoje. Atualmente, é possível saber instantaneamente, com um mero clique do mouse, como estão as cotações da bolsa de valores de Tóquio ou qual a melhor festa programada para o fim de semana em Amsterdã. Os jovens têm ao alcance de seus dedos muito mais informação do que tínhamos há cinco ou dez anos. Sua linguagem é videoclíptica, veloz, direta, imediata e imediatista. Aos três ou quatro anos de idade manejam o computador de uma maneira que causa inveja a muitos adultos (TAPSCO'T', 2010; VEEN; VRAKKING, 2009). São jovens inquietos e vorazes: querem abraçar o mundo, mas, em geral, não sabem muito bem como fazêlo.

Diante dessa realidade, o que resta a nós, professores? Restanos a adaptação a esse estranho mundo novo em que revoluções tecnológicas explodem a cada minuto. Precisamos agir e mudar, mas essa ação e essa mudança têm que ser conduzidas de maneira hábil, precisa e responsável. De nada vale a tecnologia pela tecnologia, porta segura para o fracasso. As ferramentas tecnológicas que utilizamos em nossos afazeres diários têm que ser transpostas de forma significativa e inteligente para a sala de aula e isso, sem dúvida alguma, passa pela formação adequada de nossos professores, tanto melhor se essa formação acontece ainda na graduação, concomitantemente ao 
processo de fazer-se professor, pois teremos aí, então, desde o princípio, um profissional mais completo. É indispensável que os estudantes que hoje estão nas salas de aula das universidades buscando sua formação como professores de línguas tenham a necessária informação e orientação para que entendam o novo tipo de aluno com que vão lidar ao encontrar a realidade das escolas e que saibam, ainda, manejar em seu proveito as tecnologias que nos rodeiam, tão naturais para os mais jovens. Além disso, com o contínuo avanço da UAB e de outras iniciativas em Educação a Distância, precisamos mais do que nunca de professores capacitados a lidar com tais tecnologias.

Neste artigo, então, com o intuito de contribuir com as discussões a respeito da formação tecnológica de professores de línguas, procuramos narrar uma experiência acontecida - e que segue acontecendo, não sendo, portanto, algo acabado - em uma licenciatura de língua espanhola. Nessa experiência, estão sendo criadas disciplinas para ajudar aos professores em formação a lidar com a nova realidade que nos rodeia. Também aqui, discutimos os resultados dos questionários aplicados a esses mesmos estudantes, com o objetivo de conhecer melhor suas expectativas, certezas e incertezas em torno das tecnologias. Como apoio aos nossos argumentos, usamos como referência a Teoria dos Sistemas Complexos (LEFFA, 2009; MATURANA; VARELA, 2007; PAIVA, 2007; BATESON, 2006; BEHRENS, 2005; SANTOS, 2004; JOHNSON, 2003; MORIN, 2000; 2007; LARSEN-FREEMAN, 1997; VARELA, 1994); e os conceitos de Homo Zappiens (VEEN; VRAKKING, 2009) e Geração Net (TAPSCOT'T, 2010).

\section{$1 \mathrm{Um}$ pouco de complexidade}

Se, por um lado, inquietava-nos a necessidade de criar uma oportunidade para que alunos de graduação de uma licenciatura de língua espanhola presencial pudessem ter contato com as novas tecnologias e que dessem seus primeiros passos para entender o que é e como funciona a Educação a Distância, por outro, em um nível, talvez, mais pessoal e profundo, tínhamos interesse em refletir sobre como a Teoria dos Sistemas Complexos poderia nos ajudar a nortear e a entender os resultados de um trabalho desse tipo. Nosso primeiro 
passo foi buscar compreender a representação dessa disciplina e do grupo de estudantes que se formaria como um sistema complexo. Para isso, buscamos apoio em Leffa (2009, p. 25-26), que diz:

O ensino da língua estrangeira pode também ser visto como um sistema complexo, já a partir da sala de aula. Envolve obviamente pessoas (professor e alunos), interagindo entre si através de objetos culturais consagrados pela tradição escolar (lousa, livros, cartazes), com divisão de responsabilidades (em que basicamente o professor deve criar as condições de aprendizagem e o aluno deve esforçar-se em usá-las para aprender a língua) e com normas de conduta (o regimento escolar, a LDB, os Parâmetros Curriculares Nacionais). Ainda que algumas dessas normas não sejam criadas pelo grupo e, em sua origem, estejam distantes da sala de aula (a LBD, por exemplo, originalmente aprovada pelo Congresso Nacional), seu impacto se faz presente na interação entre alunos e professores. A sala de aula não é uma redoma de vidro, um sistema fechado, impermeável ao que acontece lá fora. É, pelo contrário, um sistema aberto, vulnerável às influências do mundo externo.

Ora, se esses conceitos são aplicáveis a uma sala de aula em que acontece um processo de ensino-aprendizagem de uma língua estrangeira, concluímos que ele não é menos real no que se refere a qualquer sala de aula que pretenda desenvolver qualquer processo de ensino-aprendizagem. Queremos estudar tecnologias? Ou nosso objetivo é entender Matemática? Ou, ainda, discutir Filosofia ou Direito? Ali, no ambiente da sala de aula, estarão os professores, os alunos, os objetos culturais, as normas de procedimento, a divisão de responsabilidades e tudo aquilo que sabidamente caracteriza esses locais. Se podíamos ter certeza, entretanto, de que nossa sala de aula se configuraria como um sistema complexo, que implicações isso teria para a maneira como desenvolveríamos as aulas e o que poderíamos esperar como resultado final?

Entre os vários autores a que recorremos, encontramos em Edgar Morin (2000), filósofo francês que há muito tem se dedicado a discutir as implicações do Pensamento Complexo ou Pensamento Sistêmico 
na educação, os elementos caracterizadores dos sistemas complexos, que nos ajudariam a aprofundar nossa reflexão. Para o autor, esses sistemas caracterizam-se como abertos e dinâmicos, com grande capacidade de adaptação, auto-organizados, imprevisíveis, dotados de extrema sensibilidade às condições iniciais e a feedback. De todos esses elementos, quais poderíamos manejar para proporcionar uma disciplina que resultasse em algo realmente significativo para os estudantes?

Ainda considerando o texto de Morin (2000), podemos entender que os sistemas complexos são abertos e dinâmicos porque estão sujeitos a interferências externas: falta de energia elétrica, uma enchente na cidade, a influência de outros sistemas (família, emprego etc.). Esse, portanto, era um fator que fugia ao nosso controle. A imprevisibilidade de funcionamento do sistema, evidentemente também não poderia ser manejada. Larsen-Freeman (1997) afirma que um sistema complexo não linear se comporta de forma regular e ordenada até que algum episódio não esperado aconteça e ele, de regular e ordenado, passa a ser caótico. Depois que o episódio passa, o sistema volta a ser ordenado e regular. Sobre a natureza caótica e imprevisível dos sistemas de aprendizagem, Paiva (2007) assinala que a Teoria do Caos esclarece que mudanças mínimas podem gerar grandes diferenças e que existe uma ordem por trás da aparente desordem. Não é fácil prever o comportamento de um sistema de aprendizagem, já que, como diz Paiva (2007), existem momentos regulares e irregulares, imprevisíveis e aleatórios.

A grande capacidade de adaptação e a auto-organização, a seu turno, eram elementos que só poderiam ser observados e, talvez apenas talvez - de alguma maneira manejados quando as aulas e atividades estivessem efetivamente em andamento, já que são características que indicam o movimento de um sistema vivo que se automodifica de acordo com as circunstâncias e com toda a dinâmica que move cada uma de suas partes constitutivas, num processo contínuo de interações ativas e reativas.

Por fim, chegamos a dois aspectos que nos pareceram mais "controláveis": o feedback e a extrema sensibilidade às condições iniciais. Sobre este último, imaginamos que criar um bom ambiente de trabalho para iniciar as atividades seria de alguma ajuda para o êxito da disciplina. Para nós, isso significava planejar a disciplina de tal modo que os alunos 
participassem não apenas como espectadores, mas como elementos ativos e cocriadores de um projeto de ensino-aprendizagem que conduzisse a resultados significativos para todos. Com esse objetivo, no primeiro dia de aula, apresentamos o programa da disciplina, que, evidentemente, havia sido entregue à coordenação do curso previamente, e tentamos negociar com os estudantes a melhor maneira de fazê-lo funcionar. Mais que isso, procuramos criar um ambiente saudável baseado na interação entre iguais, deixando-os seguros de que estávamos ali para aprender com eles tanto quanto eles conosco e mostrando-lhes que estávamos dispostos a colaborar num processo de ensino-aprendizagem mais horizontal, em que a figura do professor não é o centro e motor da disciplina, mas apenas mais um elemento do sistema, um companheiro com mais experiência em alguns aspectos, mas que necessita igualmente das trocas sistêmicas para avançar (MORIN, 2007).

No que diz respeito ao feedback, Larsen-Freeman (1997) explica que o feedback positivo recebido por um sistema complexo gera evolução; por outro lado, o feedback negativo mantém o sistema estagnado. Como qualquer sistema complexo, uma sala de aula evolui e sofre influências de feedback, seja ele positivo ou negativo. No entanto, segundo Paiva (2007), nem todo feedback negativo afeta a motivação e nem todo feedback positivo promove aprendizagem. A complexidade do sistema não permite que ele funcione de forma previsível. Os aprendizes reagem de forma diferenciada a estímulos iguais, por exemplo, alguns aprendizes não reagem bem a uma avaliação negativa, outros se estimulam fazendo com que sua aprendizagem avance. No estudo feito por Paiva (2007), em um dos exemplos, o feedback negativo diminuiu a motivação da aluna, que atribuiu seu fracasso ao professor e à escola. Outro exemplo, porém oposto, é citado pela autora que conta que uma aprendiz, após fracasso escolar, tentou superar as dificuldades procurando alternativas. Como exemplo de feedback positivo no ensino-aprendizagem de línguas, Paiva (2007) mostra o papel positivo de elogios de estrangeiros relatados em muitas narrativas de estudantes, que ajudaram aos aprendizes a aumentar sua autoconfiança. Com base nisso, optamos por estabelecer uma relação dialógica e humana com os estudantes, conforme sugere Morin (2007), apontando aos alunos suas falhas para que pudessem corrigi-las, mas 
colocando em evidência seus acertos e estimulado-os na geração e no compartilhamento de conhecimentos. Acreditávamos que esse tipo de feedback poderia ser um instrumento eficiente no sentido de gerar uma alimentação contínua que levaria aos melhores resultados possíveis em um sistema complexo como o que teríamos que ajudar a construir.

Apesar de todos os cuidados iniciais e de todas as boas intenções com relação ao trabalho de feedback, entretanto, estávamos completamente conscientes de que os resultados finais não dependeriam exclusivamente de nós, afinal, como sistema complexo, todo resultado é imprevisível. A tentativa de criar as melhores e mais harmoniosas condições possíveis de trabalho não garante absolutamente nada e tanto professores como alunos têm que estar preparados para a possibilidade de que seus esforços não gerem os resultados esperados. Nas próximas seções, trataremos de narrar o que efetivamente foi feito e quais os resultados obtidos, levando em consideração o planejamento realizado com base na Teoria dos Sistemas Complexos.

\section{Complementar para crescer}

No projeto pedagógico do curso de licenciatura presencial em que trabalhamos, não estão programadas, na grade curricular, disciplinas específicas para a discussão das Tecnologias de Informação e Comunicação (TICs). Em virtude disso, e ao sentir grandes dificuldades para encontrar professores que pudessem colaborar conosco nas disciplinas de Educação a Distância, decidimos apostar nos futuros professores, elaborando um conjunto de disciplinas que nos ajudasse a mostrar a esses estudantes a nova realidade do ensino mediado por tecnologias e que os ajudassem a entender melhor o perfil dos alunos que encontrarão nas escolas de Ensino Fundamental e Médio, apontados por muitos como indisciplinados, inquietos e desrespeitosos (TIBA, 1997; WERNECK, 2005). Entre essas disciplinas, chamadas Disciplinas Complementares de Graduação (DCGs), a primeira a se concretizar aconteceu no segundo semestre letivo de 2010 e foi intitulada TICs Aplicadas ao Ensino-Aprendizagem de E/LE. É essa experiência que passamos a narrar agora.

A DCG em questão foi planejada para ser desenvolvida em 60 horas-aula e aconteceu semanalmente, às sextas-feiras à noite, na 
modalidade presencial, ainda que alguns momentos tenham sido reservados para interações on-line, conforme veremos. Entre seus objetivos estava os de reconhecer as principais TICs voltadas para ensino-aprendizagem e compreender suas aplicações e possibilidades no trabalho com espanhol como língua estrangeira, permitindo que os estudantes envolvidos pudessem levar à prática projetos pedagógicos que contassem com essas ferramentas. Para isso, a disciplina aliou estudos teóricos e atividades práticas, colocando os alunos em grupos a fim de fomentar o trabalho colaborativo, a aprendizagem por pares (MORIN, 2007).

A respeito do número de alunos, foram abertas 15 vagas, todas destinadas ao quinto semestre do Curso de Licenciatura em Espanhol, pois achamos que a metade do curso corresponderia a um momento de amadurecimento dos alunos, além de estar próximo ao estágio, circunstância em que poderiam procurar fazer uso prático das discussões realizadas. Também estipulamos como pré-requisitos que os alunos tivessem cursado as disciplinas iniciais de língua espanhola. Nossa intenção, além dos objetivos já mencionados, era a de promover mais uma instância interativa em língua espanhola para os alunos, dandolhes oportunidade de acrescentar um novo vocabulário ao seu léxico, com os termos e as expressões do mundo das tecnologias. No entanto, por alguma falha na hora de realizar a matrícula, uma aluna não pertencente ao curso de espanhol foi inscrita sem cumprir os prérequisitos estipulados. Isso nos impossibilitou de fazer as apresentações dos seminários e as discussões em língua estrangeira, obrigando-nos a usar o português por respeito à aluna, uma vez que a falha foi do sistema de matrículas e não dela. Aqui, agiu a imprevisibilidade do sistema e a necessidade de uma nova organização.

Além desse percalço, alguns alunos nos procuraram no decorrer das matrículas, pedindo que disponibilizássemos mais vagas, pois mais alunos de outros semestres estavam interessados em cursar a disciplina, apesar de ser uma DCG alocada no quinto semestre do curso. Disponibilizamos, então, 21 vagas no total, que foram completamente preenchidas. Desses 21 alunos matriculados, apenas 3 pertenciam realmente ao $5^{\circ}$ semestre. Todos os demais estavam em outros semestres, além da aluna que, conforme mencionamos, não pertencia ao curso. Percebe-se, portanto, que mesmo antes de as aulas se iniciarem, 
o sistema começou um processo de auto-organização que nos foi totalmente inesperado.

Dividida em três unidades (Conceitos Fundamentais, Tecnologias Pré-Internet e Tecnologias na Internet), a disciplina teve a maioria de seus encontros baseados em seminários apresentados pelos professores e pelos alunos. Após uma primeira aula, na qual foi desenvolvida uma conversa bastante informal para se buscar conhecer melhor aos alunos e seu nível de conhecimento com relação ao uso de tecnologias, além de procurar organizar o trabalho da forma que fosse agradável para todos (condições iniciais favoráveis), foram realizados dois seminários apresentados exclusivamente pelos professores. Na segunda das 15 aulas de 4 horas previstas, o seminário de um dos professores versou sobre técnicas para a realização de apresentações em PowerPoint, prevendo a obrigatoriedade de que os estudantes apresentassem seus seminários utilizando esse recurso para, de alguma maneira, irem se acostumando com a ideia e com o uso das tecnologias. Tinha-se a noção, a partir da conversa inicial, de que muitos alunos nunca haviam usado essa ferramenta ou, pelo menos, desconheciam algumas regras básicas para apresentar comunicações e seminários com o apoio de tecnologias, como os arquivos em formato ppt e o datashow. A aula foi presencial e prática, em um laboratório de informática, e contou ainda com uma extensão para aprofundar as discussões e para tirar dúvidas via Ambiente Virtual de Aprendizagem (o Moodle).

A terceira aula, com a apresentação do segundo professor, abordou a elaboração de pôsteres, recurso que seria usado como avaliação parcial dos estudantes, um produto final versando sobre tecnologias e ensino-aprendizagem de espanhol, resultante de todas as pesquisas e discussões realizadas ao longo da disciplina. A apresentação foi elaborada em PowerPoint e mostrada com o auxílio de um datashow. Além disso, foi feito um passeio pelos corredores do centro, com o intuito de observar os vários exemplos de pôsteres expostos nas paredes, tanto da área de Letras quanto das demais áreas, como Biologia e Pedagogia, que, possivelmente, usam esse gênero acadêmico mais do que a nossa área para divulgar suas pesquisas.

Sobre as demais aulas presenciais, 7 no total, com o devido espaço às orientações para o delineamento e elaboração das pesquisas, feitas em horários alternativos ao da disciplina, mas levadas em 
consideração para o planejamento da mesma (3 no total), os alunos apresentaram seminários, com o apoio do computador e do datashow, sobre os temas relacionados às unidades do programa da disciplina, com artigos acadêmicos recomendados pelos professores, mas com total abertura para que eles aprofundassem e trouxessem elementos novos, o que acabou acontecendo na maioria dos casos. A cada apresentação, uma discussão era realizada a fim de entender o papel, a importância, as possibilidades, os desafios, enfim, os pontos positivos e negativos da aplicação das TICs ao ensino e à aprendizagem de línguas estrangeiras, em especial de língua espanhola como língua estrangeira. Essas discussões, ao mesmo tempo em que eram feitas, incrementavam as pesquisas que os alunos iam desenvolvendo para a apresentação de seus pôsteres, bem como ajudavam a delinear as pesquisas ainda incipientes de alguns grupos.

\section{Para conhecer os estudantes}

Ainda nos primeiros dias de andamento da disciplina, pedimos que os alunos respondessem a um questionário que disponibilizamos on-line, através da ferramenta Formulário do Google Docs, com perguntas gerais, em que buscávamos obter alguns dados pessoais, informações sobre seu andamento no curso de licenciatura, além de seu nível de conhecimento em torno do tópico tecnologias. Dos 21 alunos, apenas 10 responderam ao questionário. Ainda assim, esses quase $50 \%$ dos estudantes nos deram informações bastante relevantes, que nos ajudaram a ir conduzindo a disciplina e, mais tarde, ao comparar essas respostas iniciais com as de um questionário final que ainda comentaremos, nos ajudaram a perceber seu grau de satisfação com a disciplina e seu aproveitamento. Com esse questionário inicial, ficamos sabendo que todos os que responderam cursam a Licenciatura em Língua Espanhola e Respectivas Literaturas. Entre eles, 3 pertenciam ao $5^{\circ}$ semestre, para o qual a DCG estava desenhada. Dos demais, 1 aluno pertencia ao $3^{\circ}$ semestre, 2 ao $7^{\circ}, 1$ ao $8^{\circ}, 1$ ao $9^{\circ}$ e 2 ao $1^{\circ}$.

Perguntamos também sobre as idades desses alunos, uma vez que discutimos, nos seminários, sobre as pessoas pertencentes à Geração Homo Zappiens (VEEN; VRAKKING, 2009), também conhecida como Geração Net (TAPSCOT'T, 2010). Os autores dessas teorias apontam 
que pessoas nascidas em meio aos modernos avanços tecnológicos possuem mais interesses e, por que não, habilidades, por usar diariamente a tecnologia. Nos dados observados a partir da coleta, identificamos que as idades dos estudantes variavam de 19 a 33 anos. De acordo com os supracitados autores, os alunos com idade por volta de 19 anos pertenceriam à Geração Net, sendo, para eles, o uso da tecnologia algo bastante comum e natural. Embora nem todos fossem da Geração Homo Zappiens, tivemos, com os alunos, poucos problemas relacionados ao uso do computador. Os poucos problemas pelos quais passamos estiveram justamente entre alunos que não responderam ao questionário. Um deles, por exemplo, na faixa dos 40 anos - portanto não pertencente à Geração Net -, teve mais dificuldades, mas isso foi se solucionando com o andar das aulas, à medida que o aluno obtinha mais prática e que recebia uma orientação mais específica, além dos estímulos de seus colegas.

Ainda com relação aos 10 alunos que responderam o questionário, apenas 4 não trabalhavam, sendo bastante comum em cursos de licenciatura noturnos que muitos alunos trabalhem durante $o$ dia e, normalmente, fora da área onde estão se formando. Sobre os motivos que os levaram a se matricular na DCG, tivemos respostas como a de um aluno que simplesmente precisava de horas de DCG para complementar a carga horária mínima exigida pelo curso. No entanto, o mesmo aluno afirmou que se surpreendeu positivamente com as aulas, pois "Os professores conseguiram tornar um assunto, para mim, chato, em algo agradável”. As demais respostas apresentaram justificativas como a importância de conhecerem as novas tecnologias, de atualizarem-se, para, principalmente, complementarem os conhecimentos vistos nas demais disciplinas do curso. Alguns alunos ainda enfatizaram que não há no curso disciplinas como esta, voltadas especificamente para o ensino-aprendizagem da língua espanhola, o que, para eles, é de grande importância.

Quando questionados sobre a utilidade da disciplina para sua formação como professores de E/LE, absolutamente todos responderam que a disciplina possui um papel importante para a formação deles, seja pelo simples fato de melhorar as apresentações de trabalhos acadêmicos, ou para "entender como esses recursos podem auxiliar/beneficiar o ensino atual", ou, ainda, para repensar "a 
atuação do profissional da educação nos dias de hoje", aprendendo a "aproveitar as tecnologias para deixar a aula mais chamativa e para que os alunos percebam que nós estamos no mesmo patamar de uso das tecnologias que eles, para que eles não nos achem com jeito de velhos porque não usamos os recursos tecnológicos dos quais eles tanto gostam", entre outros comentários positivos.

Sobre o perfil dos alunos enquanto usuários de computador e tecnologias correlatas, observamos que apenas um aluno não as usava com frequência, utilizando-as apenas para pesquisas, para ver noticias que não conseguiu ver na TV ou quando estava entediado. Esse aluno, por sinal, é o que tem mais idade entre os que responderam o questionário: tem 33 anos e está casado. Um segundo aluno respondeu que usa o computador "Uma vez ao dia para ver e-mail e fazer trabalhos". Outro respondeu que usa o computador quase todos os dias para acessar e-mails, ler os principais sites de notícias e fazer pesquisas e trabalhos da faculdade. Os demais - 7 alunos - usam o computador praticamente todos os dias para a comunicação pessoal/ familiar através do MSN, para fazer trabalhos, pesquisar artigos, baixar programas e livros, para comprar produtos, participar de redes sociais, jogar, ouvir música, etc.. Também constatamos que todos os alunos possuem computador com acesso à Internet em casa. Sobre os aplicativos/programas que os alunos mais usam, listamos os mais recorrentes: processadores de texto como o Word, navegadores de Internet como o Mozilla ou o Explorer, planilhas como o Excel, MSN, Picasa, Skype, softwares para tratamento de imagens como o PhotoShop e softwares para apresentações como o PowerPoint.

Já quanto à frequência do acesso à Internet, 6 alunos responderam que acessam várias vezes ao dia, 3 acessam aproximadamente uma vez por dia, e apenas 1 aluno respondeu que acessa a cada dois ou três dias. Todos os alunos responderam que possuem e-mail e todos utilizam o MSN como ferramenta de comunicação. No que diz respeito aos sites da Internet relacionados à língua espanhola que os alunos mais usam, podemos ver que todos conhecem e acessam sites nessa língua, o que é bastante positivo quando temos em mente a quantidade de informações gratuitas disponíveis on-line, hoje, nessa língua, que podem ser aproveitadas por estudantes e professores. As relações variam entre sites de canais de TV, cursos 
on-line, rádios on-line, sites de jornais, mecanismos de busca como os do Google, conjugadores verbais, dicionários, sites de instituições governamentais de língua espanhola ou sites oficiais de instituições não governamentais como a Real Academia de la Lengua Española e o Instituto Cervantes, entre outros.

Por fim, os alunos deveriam responder a uma pergunta que foi elaborada com o intuito de tentar entender, sob o ponto de vista dos estudantes, se as mudanças provocadas pelas TICs em nossa formação como professores são positivas ou negativas. Todos foram unânimes ao responder que são positivas, justificando que a tecnologia é importante para todos os segmentos da sociedade e que, na educação, cumpre um duplo papel: por um lado, como complemento para estimular a autonomia e a autoformação; por outro, como uma fonte para materiais e ferramentas que poderão ser usados em sala de aula. Ainda assim, os alunos são unânimes em afirmar que o computador não deve ser a única ferramenta de conhecimento e interesse dos professores: é preciso usar esse apoio, mas é indispensável saber manejar outros recursos, técnicas e métodos em uma sala de aula presencial.

\section{Para conhecer os resultados}

No final da disciplina, disponibilizamos um novo questionário, nos mesmos moldes, para todos os 21 alunos, mas, mais uma vez, apenas 10 responderam. Não temos como saber ao certo se os mesmos alunos que responderam ao primeiro questionário foram os que responderam ao segundo, pois não pedimos que eles se identificassem. Porém, pelas respostas encontradas, suspeita-se que sim.

Fizemos apenas sete perguntas, pedindo que os estudantes avaliassem a disciplina e também seu próprio desempenho. A primeira pergunta indagava se esse tipo de disciplina, que aborda tecnologias, é útil em um curso de licenciatura de línguas estrangeiras. Os alunos deveriam justificar suas respostas. Todos responderam que sim e justificaram, resumindo os argumentos por eles apresentados, que a disciplina enfatizou temas que não seriam trabalhados na matriz curricular do curso, dando a oportunidade de que conhecessem as potencialidades das TICs para a sala de aula de línguas estrangeiras. Uma aluna sublinhou o fato de que a disciplina seria importante para qualquer licenciatura, 
pois, já que a tecnologia está modificando os alunos, os professores devem estar a par do que acontece fora da sala de aula. Alguns destacaram as potencialidades da Internet para o caso específico das línguas estrangeiras, como os materiais reais aí disponíveis, que aproximam o aluno à língua como ela acontece.

Sobre o ponto discutido em aula com relação ao novo perfil dos alunos que chegam à escola hoje, perguntamos se os estudantes acreditam que essas discussões serão úteis para quando começarem a desempenhar a profissão. Mais uma vez, todos responderam positivamente, argumentando da importância de se discutir a realidade da escola e dos alunos que os futuros professores encontrarão. Nossos alunos também argumentaram que essa nova geração, que já está nas escolas, possui necessidades diferentes das que tínhamos quando éramos alunos de escola. Uma estudante, em especial, enfatizou que "devemos entender como esses alunos se comportam, como a sociedade em que eles vivem está passando por modificações constantes e como isso reflete nas atitudes deles em sala de aula".

A terceira questão tentava perceber se os alunos, mais adiante, como profissionais da educação, teriam condições de utilizar algo dos recursos estudados, nas escolas em que trabalharão. Todos, mais uma vez, responderam afirmativamente ao questionamento. $\mathrm{Na}$ quarta questão, sobre se a disciplina, de alguma forma, foi útil no que se refere à relação dos estudantes da graduação com o computador e com a Internet, dos 10 alunos, 5 responderam que sim, que a disciplina modificou a forma como eles se relacionam com essas tecnologias. Um aluno afirmou que a disciplina "direcionou minha atenção a novas possibilidades de aprendizado de forma agradável e gratuita”, enquanto outro disse: "passei a enxergar possibilidades de uso da internet em sala de aula que antes não sabia como fazê-lo". Um terceiro aluno afirmou que "esta disciplina me auxiliou a perceber a infinidade de ferramentas que existem que podem ser utilizadas em sala de aula”. Outro, ainda, contou que agora não mais guarda documentos no computador, pois aprendeu a usar o Google Docs: "Acho chique!", relatou o aluno. Para 4 alunos, porém, a disciplina não modificou sua relação pessoal com o computador e com a Internet, mesmo assim, colocaram que a disciplina possibilitou novas descobertas e mudanças de concepções sobre o uso de tecnologia em educação. Entre todos, 
apenas um aluno registrou uma reclamação, alegando que durante toda a disciplina lhe foi oportunizado conhecimento teórico, mas pouca prática. Afirma ele: "não fomos para um laboratório, dentro da UFSM, na frente de um computador para fazer algo". Na verdade, a segunda aula foi realizada num laboratório de informática, mas não no centro onde as demais eram realizadas. Essas aulas, aliás, aconteciam em uma sala multimídia, com datashow, som e outros recursos tecnológicos. No entanto, é possível compreender a reclamação do aluno, muito embora não fosse a proposta da disciplina prover treinamento em laboratório, pois o Curso de Letras não possui um laboratório próprio e os que existem na universidade são de difícil acesso, pelo fato de a maioria dos demais cursos serem diurnos e esta disciplina ter sido realizada, como se comentou, nas sextas-feiras à noite.

Sobre os recursos tecnológicos estudados na disciplina, todos em nível teórico e por meio de demonstrações, os alunos disseram ter mais interesse pelos seguintes: ferramentas de autoria para professores (4 menções), podcasts ( 3 menções), webquests ( 2 menções), vídeos (2 menções), blogs (2 menções), Google Docs (1 menção), apresentações em ppt (1 menção), Livemocha (1 menção). Na pergunta seguinte, buscava-se entender se, desses recursos, os alunos começaram a usar algum por conta própria, mesmo sem orientação específica. Dos 10 alunos que reponderam ao questionário, 5 responderam que não. Um destes destacou que "Ainda não... mas pretendo utilizá-los, principalmente na etapa de estágio”. Outros 2 afirmaram que ainda não, por falta de tempo. Entre os que passaram a utilizar as ferramentas, um colocou que começou a utilizar o Livemocha, espécie de comunidade on-line de apoio para aprendizagem de línguas, e outro afirmou que "A maioria das vezes que utilizei esses recursos foi na elaboração de aulas na disciplina de prática docente, a ferramenta que predominou foi o podcast". Outro aluno destacou o PowerPoint e outro, ainda, o Google Docs e o HotPotatoes. Um dos estudantes afirmou que passou a usar "os programas para criar exercícios e os podcasts, pois permitem que o aluno tenha contato com diálogos/ monólogos autênticos, que o aluno tenha contato com uma fala produzida sem intenções didáticas, uma fala mais natural. Baixei o Ardora e estou 'intentando' utilizar, mas estou bem curiosa com os WebQuests (não sei se é esse o nome)". 
A última pergunta do questionário indagava se a disciplina, ao fim, preencheu as expectativas iniciais. Um aluno registrou que tinha "uma ideia bem diferente do que realmente aconteceu". Ele achou que "íamos para um laboratório, na frente de um computador, bem como querem que os professores do ensino fundamental ou médio façam com seus alunos". Entre os demais, 7 alunos informaram que a disciplina atendeu as suas expectativas iniciais. Uma destas alunas colocou que alguns assuntos poderiam ser apresentados nos seminários pelos professores e não por colegas, como aconteceu. Outros 2 alunos chegaram a mencionar que a disciplina superou suas expectativas. Um deles destacou que, por ter tido a oportunidade de buscar informações sobre determinados assuntos, sem receber pronto dos professores e dos colegas, conseguiu aprender mais. Afirmou que "Se fosse uma disciplina que ensinasse como usar cada tecnologia regra por regra, mostrando cada função de cada ferramenta eu não iria aprender nada". O segundo destes alunos justificou dizendo: "não pensei que descobriria tanta coisa nova em um único semestre", mas ressaltou que "deveria ser uma disciplina ofertada nos semestres inicias do curso”.

\section{Concluindo o semestre}

Além do questionário, que, como se viu, foi disponibilizado para que os estudantes o respondessem voluntariamente, a atividade principal de encerramento do semestre foi a apresentação dos pôsteres. Foi interessante perceber como, dando total liberdade aos estudantes, seus trabalhos em torno das TICs foram se construindo a partir de seus próprios interesses, resultando em trabalhos interessantes, criativos e significativos. Estudantes que trabalham com produção de material, por exemplo, se interessaram em pesquisar sobre direitos autorais em meio digital, enquanto estudantes que trabalham em projetos com deficiência visual foram buscar dados mais aprofundados sobre a relação desse público com as tecnologias.

Nessa produção final, dividimos grupos de alunos entre os dois professores, na medida em que eles escolhiam seus temas para a realização de suas pesquisas. As divisões levaram em consideração as experiências de cada professor e foi realizada para que os grupos tivessem uma orientação mais dedicada, ficando da seguinte forma: 


\section{PROFESSOR 1}

Grupo 1 - Perspectivas e eficácia das videoaulas na EaD

Grupo 2 - A nova geração de estudantes e sua relação com o vídeo

Grupo 3 - O laboratório de informática nas escolas

Grupo 4 - O ensino de espanhol para cegos por meio das TICs

\section{PROFESSOR 2}

Grupo 1 - Os programas de tradução e o tradutor profissional

Grupo 2 - Uso das TICs no ensino de línguas estrangeiras

Grupo 3 - Crenças de professores sobre TICs

Grupo 4 - Professores x alunos e o uso das novas tecnologias

Grupo 5 - Direitos autorais em meio digital

As apresentações foram feitas em 2 dias de aula. Os alunos demonstraram os resultados de suas pesquisas através de pôsteres digitais projetados por meio do datashow, e suas apresentações contaram com intervenções dos colegas e dos professores. Essas apresentações foram amplamente satisfatórias. O empenho mostrado pelos alunos, desde o processo de pesquisa, passando pela diagramação dos pôsteres e pela apresentação em sala de aula, demonstrou um amadurecimento impressionante, não apenas no que tange aos conhecimentos específicos envolvidos, mas em vários outros aspectos, como o desenvolvimento de habilidades de pesquisa, capacidade de expressão e defesa de um ponto de vista, enfim, todos aqueles requisitos que fazem um bom pesquisador. Os estudantes, em geral, não se contentaram em cumprir com o básico: foram além e, em alguns casos, surpreenderam. Parecia que lhes dava verdadeiro prazer tentar superar-se e superar os outros grupos, originando-se daí uma espécie de competição bastante saudável, que levou a um final realmente exitoso para a disciplina.

Para concluir todo o trabalho, após as apresentações dos pôsteres, promoveu-se uma autoavaliação, em que os alunos deveriam atribuir notas - devidamente justificadas - para os seguintes critérios: pontualidade, presença e assiduidade na aula; comprometimento com a disciplina; preparação das apresentações dos seminários; participação nas apresentações dos colegas. Todos os alunos realizaram essa autoavaliação e, de maneira geral, foram bastante críticos com o seu desempenho na disciplina, demonstrando comprometimento com os colegas e com os professores. 


\section{Considerações finais}

Por tudo o que foi colocado até aqui, é fácil notar que para nós, que desenvolvemos e colocamos em prática a disciplina, o resultado foi recompensador. Mais importante que isso, entretanto, foi perceber que, para os estudantes, ou pelo menos para a maioria deles, houve uma sensação similar à nossa. A preparação da disciplina sob a ótica da Teoria dos Sistemas Complexos e a conscientização, dela decorrente, de que é necessário fazer do processo de ensino-aprendizagem algo mais humano e mais democrático tornou, para todos, o trabalho mais prazeroso e mais rico. $\mathrm{O}$ respeito à regra da sensibilidade às condições iniciais e ao processo de feedback positivo, sem dúvida, colaboraram para o êxito das atividades. Além disso, todas as questões pertinentes aos sistemas complexos, elencadas por Morin (2007), foram identificadas ao longo do trabalho: a auto-organização, quando percebemos que o grupo foi praticamente se constituindo sozinho, independente dos requisitos que havíamos previamente elaborado; a capacidade de adaptação, burlando com criatividade a falta de todos os recursos tecnológicos que seriam esperados em uma disciplina desse tipo; a abertura e dinamicidade, como resultado de interferências de sistemas externos, a exemplo do mencionado erro na matrícula e de outras situações não apenas vividas pelo grupo, mas por cada integrante individualmente, o que interfere diretamente no sistema como um todo; a imprevisibilidade dos resultados, pois, ainda que se tentasse fazer o melhor, uma das alunas desistiu no meio da disciplina, muito embora, para a maioria, a conclusão tenha sido positiva.

No que diz respeito aos alunos e ao trabalho com a disciplina, acreditamos que nossos objetivos iniciais foram cumpridos dentro do possível e temos como elemento de reforço para essa impressão a própria palavra dos estudantes. Parece-nos que eles se tornaram mais conscientes das tecnologias atuais e de tudo o que isso pode proporcionar nos meios educacionais, e estamos certos de que eles poderão utilizar com acerto essas ferramentas tanto nas salas de aula presenciais como na Educação a Distância. Quanto à pesquisa e nossa reflexão em torno da Teoria dos Sistemas Complexos, estamos seguros de ter percebido, na prática, todos os elementos que estudamos e analisamos teoricamente, o que nos faz crer que essa teoria tem muito 
a acrescentar no campo da educação, não apenas no ensino de línguas ou de tecnologias, mas de forma global. Qualquer disciplina, qualquer professor, qualquer grupo de alunos pode se utilizar dela para ter uma visão mais clara de como acontece a aprendizagem. Não é à toa que, entre seus expoentes, estão não apenas filósofos ou pedagogos, mas biólogos, físicos, historiadores, linguistas, etc.. Ainda assim, mais pesquisas merecem ser feitas com base nos sistemas complexos.

Por fim, vale a pena mencionar que esse trabalho encontrou continuidade ainda no primeiro semestre de 2011. Uma disciplina envolvendo o uso de Ferramentas de Autoria para Professores (FAPs) e Webquests (WQs) foi ofertada aos estudantes, tendo como prérequisito a disciplina que aqui foi apresentada. Ainda sob a perspectiva dos sistemas complexos e agora sendo desenvolvida em um laboratório de informática, a disciplina promete trazer novidades às nossas pesquisas, o que pretendemos divulgar futuramente. Seja como for, independente de complexidades ou aprofundamentos teóricos, parece-nos importante destacar que o grande objetivo de pensadores como Morin, Varela e Maturana, entre outros, é que se recupere a visão de que é possível originar, ainda, uma verdadeira revolução na forma como se ensina e se aprende, desde que o ser humano e o mundo sejam percebidos em seu aspecto integral, de maneira holística, como um todo coordenado e interdependente, e não como peças autônomas e desconectadas.

\section{Referências}

BATESON, G. Espíritu y naturaleza. Buenos Aires: Amorrortu, 2006.

BEHRENS, M. A. O paradigma emergente e a prática pedagógica. Petrópolis: Vozes, 2005.

JOHNSON, S. Emergência: a dinâmica de rede em formigas, cérebros, cidades e softwares. Rio de Janeiro: Jorge Zahar, 2003.

LARSEN-FREEMAN, D. Chaos/complexity science and second language acquisition. Applied Linguistics, Oxford, Oxford University Press, v. 2, n. 18, p.141-165, 1997. 
LEFFA, V. J. Se mudo o mundo muda: ensino de línguas sob a perspectiva do emergentismo. Calidoscópio, v. 7, n. 1, p. 24-29, jan./abr. 2009.

MATURANA, H. R.; VARELA, F. J. A árvore do conhecimento: as bases biológicas da compreensão humana. São Paulo: Palas Athena, 2007.

SANTOS, A. Didática sob a ótica do pensamento complexo. Porto Alegre: Sulina, 2004.

MORIN, E. Da necessidade de um pensamento complexo. In: MARTINS, F. M.; SILVA J. M. (Orgs.). Para navegar no século XXI. Porto Alegre: Sulina/Edipucrs, 2000.

. Educação e complexidade: os sete saberes e outros ensaios. São Paulo: Cortez, 2007.

PAIVA, V.L.M.O. As habilidades orais nas narrativas de aprendizagem. Trabalhos em Lingüistica Aplicada, v. 46, n. 2, p. 165-179, 2007.

TAPSCOTT', D. A hora da geração digital. Rio de Janeiro: Agir, 2010.

TIBA, I. Disciplina, limite na medida certa. São Paulo: Gente, 1996.

VARELA, F. Conhecer as ciências cognitivas: tendências e perspectivas. Lisboa: Instituto Piaget, 1994.

VEEN, W.; VRAKKING, B. Homo Zappiens: educando na era digital. Porto Alegre: Artmed, 2009.

WERNECK, H. Pulso forte e coração que ama: a indisciplina tem jeito. Rio de Janeiro: DP\&A, 2005. 